\title{
STORIES FOR CHANGE: A THEMATIC ANALYSIS
}

\author{
Ankita Nandy, \\ Research Associate, Bharti Institute of Public Policy, \\ Indian School of Business, Mohali, India
}

DOI: $10.37648 /$ ijrssh.v10i02.022

Received: $20^{\text {th }}$ March, 2020; Accepted:26 ${ }^{\text {th }}$ April, 2020; Published: $27^{\text {th }}$ April,2020

\begin{abstract}
Prevalent beliefs that assign attributes like meekness and weakness to women, limit their resources towards individual growth and wellbeing. This stereotyping provides fertile ground for the violation of human rights. As these stereotypes populate print and digital media, the catalogues of the lives of the ordinary on the Facebook pages of Humans of Bombay, Humans of Pakistan, Humans of Karachi and Humans of Bangalore provide alternative perspectives which can challenge such stereotypes and coax people into gradually discarding them. This work performs a thematic analysis on a subset of such stories, narrated by women, on these pages.
\end{abstract}

Keywords: Facebook, gender stereotyping, social change, thematic analysis, women

\section{INTRODUCTION}

(Cusack, 2013) defines stereotype as "a generalized view or preconception about attributes or characteristics that are or ought to be possessed by members of a particular social group or the roles that are or should be performed by, members of a particular social group". These stereotypes shape the behavior of the members of the society toward each other, with both positive and negative outcomes. Gender stereotyping ascribes roles to men and women, simply because they are men or women. While the prevalence of stereotypes opens both restrictions and privileges, when they negatively impact the personal wellbeing and growth of an individual, they create scenarios befitting to the violation of human rights. In a patriarchal society, the general belief of women being subordinate to men exposes them to discrimination, violence and abuse, and disproportionate access to food, healthcare and education. Built and ossified over centuries, these stereotypes are so deeply ingrained in the society that when UNICEF conducted a survey to gather the public opinion, it found majority of women justified physical harm inflicted on them by their husbands for being disobedient in bed or burning the food (Clifton, 2012).

An investigation into these prevalent stereotypes by (Ali et al., 2011). shows that a "good" woman is the one who silently submits to her male relations and fulfils their physical and sexual, sometimes financial, demands, always putting forth their comforts before her own. Although yelling at or beating one's wife is considered "bad", the mother instilled a fear of father's aggression to discipline the children. Thus, these gender stereotypes are preserved and handed over to the next generation by both men and women.

Gender stereotypes are socially constructed and imbibed through exposure. Besides the behavior learnt by mimicking adults, young minds are trained to adhere to these stereotypes through popular media such as movies, advertisements, books et cetera. In an analysis of textbooks, in English, from Pakistan, Bangladesh, Indonesia and Malaysia, used at secondary level of education, issued by the respective governments, (Islam \& Asadullah, 2018) found pro-male gender bias and under-representation of women in the content. An analysis of Wikipedia pages of Hindi movies in (Bhattacharya, 2017) found gender bias embedded in the characters' description, occupation and actions, and female characters had lesser roles but higher visibility on posters/trailers to pull the audience to the theatres. The objectification of women (and men) sells detergent, music CDs, soft drink and deodorant of four popular brands, respectively (Purohit, 2017). As the industry made women-centric films, they faced opposition on religious and social grounds, poor funding, high censorship and therefore, ended up occluding the social 
issues behind the glamour and charm of the female characters to ensure commercial success and skirt controversy (Sarkar, 2012).

Though the media is reflective of the society, it influences it as well- copycat crimes and social marketing campaigns being indicative of the power of media in creating social change (Kraidy, 2002). Thus, the presentation of alternative content can encourage young minds to question existing stereotypes and gradually discard them. While print and digital media are prone to censorship and need to adhere to societal norms to gain commercial success, social media is less prone to censorship and offers greater liberty in expressing one's opinion. This makes it an excellent avenue for women (and men) to share their own unique perspectives, without conforming to the ideals set by patriarchy.

Social media platforms facilitate the participation and engagement of the crowd to create innovative campaigns at low budgets and create a far-reaching impact (Bresciani \& Schmeil, 2012). Such a social campaign began when Brandon Stanton started the Humans Of New York Facebook page (https://www.facebook.com/humansofnewyork/) in 2010. Posting photos of common people, whom we otherwise pass without a second glance every other day, accompanied by mini narratives about their lives, readers in one corner of the globe could relate to the thoughts of someone in another corner, generating awareness, empathy and support. The roving photographer could reach out to those who may not have accessed social media to tell their own stories due to a variety of concerns such as, limited access, concerns related to privacy, cyberbullying and addiction, and a disinterest in self-presentation (Turan, Tinmaz \& Goktas, 2013).

The success of HONY triggered similar initiatives in different parts of the world, of which Humans of Bombay (https://www.facebook.com/humansofbombay/), Humans of Pakistan (https://www.facebook.com/HofPak/), Humans of Karachi (https://www.facebook.com/humansofkhi/) and Humans of Bangalore (https://www.facebook.com/humansoblr/) have been identified as resources for the current work. Focusing on a subset of the posts which feature women protagonists, thematic analysis explores the commonalities that appear across their stories, and their potential in challenging stereotypes.

\section{MATERIALS AND METHODS}

This work uses a set of 204 posts gathered from the Facebook pages of Humans of Bombay, Humans of Bangalore, Humans of Pakistan and Humans of Karachi. Posts featuring interviews captured on video were excluded. The analysis was performed on only the text, thus the images, links, hashtags et cetera were discarded.

The procedure of thematic analysis has been adopted from (Braun \& Clarke, 2006). It is a six phased processfamiliarization with data, generation of initial codes, search for themes, review of themes, defining and naming of themes and producing the report. The collected posts were read repeatedly to identify the events described, emotions conveyed, and various characters introduced in the narrative. Key aspects of the story were noted. Based on the key features, labels were assigned to the story, which were refined through each further reading. As theme is an abstract concept, labels could be organized in several ways. As this analysis aims to focus on the protagonist and not on the adversity/ adversary, it is attempted to organize the content into themes which describe the journey, and not the circumstances that led to it. Review of themes, themes are cross checked with labels to ensure their relevance. These themes are described as crisp sentences. Using snippets from the stories, the themes are elaborated.

\section{RESULTS AND DISCUSSION}

Being linear narratives in first person, the 204 posts collected cover diverse issues, such as colorism and body shaming, restricted physical activity due to amputation, deformity or muscular dystrophy, illnesses such as cancer, epilepsy and depression, criminal offences such as domestic violence and sexual abuse/harassment as well as social evils like patriarchy, homophobia, superstition and forced prostitution.

The photographers build noteworthy camaraderie with the protagonists to capture their experiences in vivid detail. A woman gives glimpses into her happy childhood with her adoptive family, "The day my baby brother was born, I was beyond excited. To me, he was mine and my parents could 'borrow' him when they needed to."

As the protagonists describe their struggles and achievements, several organizations such as Smile Train (https://www.smiletrainindia.org/), $\quad$ SHEROES

(https://sheroes.com/), Sindh Union Council and Community Economic Strengthening Support Programme (https://success.org.pk/) and Karachi Down Syndrome Programme (https://www.kdsp.org.pk/) find mention which have supported these women in their endeavors. Several speakers themselves head start-ups and non-profit organizations, such as Reading Room Project and Ayesha Chundrigar Foundation (ACF) Animal Shelter, thus these posts create awareness/publicity for these initiatives. The longest narrative is of 895 words from the co-founder of "Care for Health", a non-profit organization in Karachi raising awareness about mental health issues in Pakistan, 
while the shortest is of 71 words from a Pakistani woman voicing her opinion on the struggles of being (or aspiring to be) an independent woman. Six themes emerged from this analysis, as described below.

\section{A. Women are more than just their physical bodies.}

Traditionally women have been judged on the way they look, such as their skin color, hair, agility and shape. Success being an outcome of fair skin rather than competency- a persistent theme in advertisements for cosmetic products (Jaggi, 2013)- equates the woman's worth to her physical charm and thus, demeans her value as an individual.

This ideology is challenged by several protagonists who have succeeded in the field of fashion and modelling despite their physical attributes, deformities and disabilities. Unsolicited advice on improving their looks, or repeated taunts on how their lives are doomed for being "different" did leave some confused and disheartened in their growing years, however, they eventually discovered self-worth and beauty beyond just looks.

Quoting one of the contributors, "I'm happy the way I look, whether it's the color of skin or the way my hair curls. I like the way I dress, I spent a good number of years to find a hairstyle that I like, so why am I changing myself to conform to society? People would tell me I shouldn't be so active on social media because no guy would want to date me. I think only an idiot would judge anybody from their Facebook page, rather than meeting me."

A woman who is physically restricted to a wheelchair but her spirit flies high, says, "At a young age, my life took an unexpected turn and my only choices were to let my disability dominate my life or to let it transform my life. I chose the latter. So far, I've visited 33 countries and I aim to complete 50 before my birthday this year! It's been a complete roller coaster so far, but hey -- I'm enjoying the ride on my very own batmobile!" The realization that physical constraints due to amputation, an incurable disease or an accident doesn't limit their capabilities as an individual has liberated them from naysayers.

\section{B. There are women unafraid to break conventions.}

Traditionally women are identified by their male relations, as his daughter, wife or mother. Their roles are restricted to household responsibilities, childrearing and supporting her husband. Many women, however, have embraced roles unusual to their social circles and created an individual identity. Their unconventional choices were related to their professions, vocations, sexual preferences and attitudes towards superstitious practices and cultural norms. Though some of them have taken up these roles as a need of the hour, such as loss of household income or a family catastrophe, others have followed their passions.

May it be the girls in the rural areas near Gilgit, Pakistan who fight the community beliefs and take midwifery as a profession, or the girl who chased her passions to become the first woman professional poker player in India, these women have battled the orthodox views to fulfil their dreams. Unanimously they discovered that the society which demotivated them during their journey, later came forward to praise/ thank them when they reached their goals.

An avid biker notes, "I have five bikes, but I also pray five times a day. I practice my religion, I cover my head, but I wear a leather jacket and biker boots too. I'm doing what my heart tells me to -- it's as simple as that. Why do I need a label or a tag to define me?"

As these women explored new avenues, they could shatter other preconceived beliefs. A practicing surgeon says, "While some people think doctors should desensitize themselves to the suffering of their patients to become successful professionals, I don't think that's true! The only way you can be a good health-care professional is to first become a good human being. You need the ability to empathize with your patients."

As their struggles inspire the younger generation of girls (and boys), they shatter the general ideology of one's gender deciding one's capabilities. A woman bus driver puts it in words, "Driving a bus or a truck is not a man's job. Anyone can do it -- and we shouldn't be afraid to do it either. We're immensely strong, and it's time we own up to it."

\section{There are women actively helping others.}

A sex worker recalls a terrifying episode in one of the posts. "One night, after making a deal with my client I took him in a car, and we were headed to his place. Once we were at his place, I noticed that there were a bunch four other men there, all drunk out of their minds. I had started to protest but by then it was too late, I was physically beaten, and gang raped by five of them despite telling them that I had HIV. They taunted me saying that I was lying and were in a hurry to go between my legs. Once the ordeal was over, I escaped by hiding myself in a truck and went to the nearest police station. I had shown the bruises I had on my body and private parts and asked for the help. Their reaction was, 'You are a sex worker, how does this classify as rape when you are whoring around town for money?' My case was never registered and investigated." Gender based violence is the most widespread violation of human rights, which, on account of rigid social norms and male chauvinism, goes unreported or unrecorded and thus unchecked (Heise, Ellsberg \& Gottmoeller, 2002). Such 
violence leads to physical, reproductive and emotional trauma and when inflicted over generations becomes a culturally accepted practice. Today this woman actively spreads awareness about HIV and advocates for the rights of sex workers.

Contrary to the popular belief of women being aloof and self-centered, and harboring animosity towards other women, these posts show women helping each other and contributing towards the society. Survivors of abuse, domestic violence, rare disorders, cancer, bullying et cetera are spreading awareness to save potential victims and advocating for a positive change. Social media plays an active role in their agenda. One woman took to Instagram to share her experiences in an abusive relationship, and says, "My DM's were full of girls sharing their stories about how he had abused and molested them too! This whole thing had become so much bigger than I had expected. There was a minor involved as well." This led to the abuser being exposed as well as punished.

Another woman, who fought body shaming all her life, says, "In 2016, I started my online blog which focused on body positivity and how to accept yourself the way you are. Through my blog, I've interacted with so many young boys and girls who suffer from an inferiority complex because of the size of their bodies. I will never forget one of the first messages I got from a young girl - 'Today, I wore a sleeveless dress for the first time in my life, and it felt so great. I have stopped caring about what other people think about me and have decided to live my life the way I want to.' Looking back, I wish I had started my blogging journey earlier on."

As these women bear personal losses, such as public aggression, in the course of their struggle, it is their sense of purpose that keeps them on track. A healthcare professional states, "When I put on my uniform, I feel very strong. I feel that Allah gives you this sense of strength via the uniform at times. You realize that this is your responsibility, that this mother is counting on you to help her bring her child into this world. Even if I am feeling sick someday, I drag myself out of the bed and wear the uniform and suddenly, I feel much better. It renews my sense of purpose to help people."

As these women devote their lives towards social upliftment, they become role models and inspirations for the younger generations, thus promoting the spirit of selfless giving. A young student says, "I opted sociology because of my mother's work. She empowers other women of the valley and gives them vocational trainings and skills."

\section{Women are propelled by their hope and optimism.}

While a young woman laments in resignation, "I cannot help but feel that my current appalling luck is a result of having angered and disappointed my parents," several protagonists demonstrate the toughness of spirit, "I've already lost a lot in this fight, but I have faith that at the end of the day - the good will triumph over evil. And we will get what we deserve, no matter what." Thus, not every story ends like a fairy tale, but the torchbearer doesn't give up. Hope is what keep women active in their battles, which last years and often consume all their lives. Survivors of acid attacks, domestic violence, forced prostitution and severe disabilities find empowerment in their belief in a better tomorrow- for themselves, their children and those in the same shoes as their own. They take their failures as lessons for future battles, which keeps them motivated to dream big. The co-founder of StyleBank puts this positivity in her brief response," If you wanna be taken seriously, just ask for it."

\section{E. There are men who support women.}

The advertisements which present women as brainless objects of desire or submissive caregivers build the idea of masculinity by attaching it to aggression and sexual predation (Purohit, 2017). Thus, gender stereotypes are harmful and restrictive for all genders.

These posts present numerous examples of men, who as fathers, brothers, husbands, friends or random passers-by, have provided women with support and motivation in fulfilling their dreams. In doing so, these men also fight the society which is quick to judge them as effeminate or incapable of being able to control the women in their lives, yet they extend their support in whatever ways helpful. A woman taxi driver recalls an elated customer, "Once, an elderly gentleman got into my taxi and said, 'Back in my village I've heard that women are making progress in cities; but this is the first time I've witnessed it. Seeing you drive fills me with pride!"”

In their growing years, as boys become men, they too fall prey to patriarchal ideas, however, as one protagonist observes, her father underwent a change in attitude towards education of girls through his interactions with his employer. Therefore, it is never too late to integrate progressive thinking in one's life.

\section{F. A supportive family/community can make startling difference to one's life.}

Though gender-based stereotypes are ubiquitous, women have found positive morale support in their endeavors in their parents, siblings, friends, partners and community, which proves that though few, there are people who don't agree with these stereotypes. As an example, the EU funded 
SUCCESS empowered numerous rural women to support their families financially and raise the quality of living in their respective villages. These women then became the agents of change for other households and spread the goodwill. "I had to fight with the society, as they did not approve when my girls joined the hostel. However, later after seeing my success, other women asked for my support to connect them with the SUCCESS programme," quotes one of the beneficiaries.

The impact positive family support can have in one's life is elaborated by incidents where the protagonist didn't get it. A survivor of child sexual abuse recalls, "Out of frustration and unrest, I couldn't help but tell my mother about what had happened to me years ago and by whom. To my surprise, she didn't believe me. My very own mother didn't believe me! I wanted my voice to be heard but she made me quiet by saying "You couldn't disclose it back then, so you must not disclose it even now and I don't want to hear a word of it." I was shocked after listening to her lack of empathy." Such stories provide lessons to both children and their parents towards cultivating trust and understanding in their relationships.

Our family members shape our understanding of the world in our formative years. If they imbibe a positive outlook, it stays throughout our lives. We hear from a transman who underwent gender corrective surgery, "The journey from being Kshama to now becoming Samar, has taught me one thing -- you have to do you have to do and not bother about what other people think. But most importantly, you need to

HONY had inspired numerous initiatives of cataloguing experiences, though this study gathers content from just four. Further, the exclusion of stories with male protagonists (who might have shared some inspiring women-centric story) and those recorded as videos, limits the coverage. Further as the focus of this work is on gender stereotyping of women, the struggles and feats of those who fight gender stereotyping and objectification of men have been excluded. These limitations can be overcome with wider study in the future. Similar content on other digital platforms can add valuable insights towards the ongoing have the courage to be honest with your loved ones, no matter what the problem is -- cause when those who love you accept you unconditionally - you become invincible!" The cumulative output of this analysis is the demonstration of the steady progress towards the dismantling of gender stereotypes in the society brought about by made by average folks. Social media presence ensures this content spreads out to various demographics and geographies. Stories have been powerful media for transmitting knowledge, sharing experiences and inspiring action. The storytelling through these Facebook pages and other popular platforms, such as Instagram, can encourage people to rethink the roles women (and men) can play in the society.

\section{CONCLUSIONS}

The thematic analysis of women narrated stories on Humans of Bombay, Humans of Pakistan, Humans of Karachi and Humans of Bangalore yields six broad themes. Women are breaking their traditional image of being submissive and servile. They are changing the standard conventions of physical beauty. Women are helping other women in stepping out of their patriarchal cages, their family and friends are supporting them in doing so and several have listed men as their allies. These narratives have the potential to inspire women and men to gradually dismantle prevalent stereotypes and appreciate individuals for their capabilities irrespective of their gender.

\section{LIMITATIONS AND FUTURE WORK}

efforts towards dispelling stereotypes, and the outcomes of such initiatives.

Besides gender stereotypes, there exist other stereotypes, such as those related to race and demography, as demonstrated by a small subset in the data, "International news was full of gruesome images from Iraq, Libya and Pakistan so I was quite skeptical when I had the chance to meet someone from Pakistan. They told me that there is a different Pakistan beyond the news. When I visited the country myself, I was surprised to discover this was true." Similar studies on the content on these platforms can attract attention towards problems mostly swept under the carpet in popular perception.

\section{REFERENCES}

[1] Cusack, S. (2013). Gender stereotyping as a human rights violation. United Nations Human Rights, Office of the High Comissionate, Año, 13-30.

[2] Clifton, D. (2012). Most Women in Afghanistan Justify Domestic Violence. Population Reference Bureau.

[3] Ali, T. S., Krantz, G., Gul, R., Asad, N., Johansson, E., \& Mogren, I. (2011). Gender roles and their influence on life prospects for women in urban Karachi, Pak0istan: a qualitative study. Global health action, 4(1), 7448. 
[4] Islam, K. M. M., \& Asadullah, M. N. (2018). Gender stereotypes and education: A comparative content analysis of Malaysian, Indonesian, Pakistani and Bangladeshi school textbooks. PloS one, 13(1).

[5] Bhattacharya, A., "After analysing 4,000 films, researchers confirm that Bollywood movies are still crazy sexist", October 23, 2017, Quartz India, accessed on https://qz.com/india/1104106/bollywood-has-a-very-real-gender-probleman-analysis-of-4000-films-reveal/ on 28th February, 2020

[6] Purohit, D. (2017), Media as One of the Reasons for Prevalence of Female Objectification, Scholars Journal Arts, Humanities and Social Sciences, 5(10B):1390-1394

[7] Sarkar, S. (2012). An analysis of Hindi women-centric films in India.

[8] Kraidy, M. M. (2002). Social change and the media.

[9] Bresciani, S., \& Schmeil, A. (2012, June). Social media platforms for social good. In 2012 6th IEEE International Conference on Digital Ecosystems and Technologies (DEST) (pp. 1-6). IEEE.

[10] Turan, Z., Tinmaz, H., \& Goktas, Y. (2013). The reasons for non-use of social networking websites by university students. Comunicar. Media Education Research Journal, 21(1).

[11] Braun, V. and Clarke, V. (2006) Using thematic analysis in psychology. Qualitative Research in Psychology, 3 (2). pp. 77-101. ISSN 1478-0887.

[12] Jaggi, R. (2013). Representation of Women in Indian Television Advertising: Situating the 'Discourse'in the 'Fair \& Lovely Ad Campaign'IMS Manthan,(The Journal of Compt Science, Management \& Journalism), Vol 8, Issue 2 (Dec 2013). Journalism, 8(2).

[13] Heise, L., Ellsberg, M., \& Gottmoeller, M. (2002). A global overview of gender- based violence. International Journal of Gynecology \& Obstetrics, 78, S5-S14. 